\title{
Identification and ranking of extraordinary rainfall events over northwest Italy: the role of Atlantic moisture
}

Article

Published Version

Pinto, J. G., Ulbrich, S., Parodi, A., Rudari, R., Boni, G. and Ulbrich, U. (2013) Identification and ranking of extraordinary rainfall events over northwest Italy: the role of Atlantic moisture. Journal of Geophysical Research, 118 (5). pp. 20852097. ISSN 0148-0227 doi: https://doi.org/10.1002/jgrd.50179 Available at https://centaur.reading.ac.uk/32738/

It is advisable to refer to the publisher's version if you intend to cite from the work. See Guidance on citing.

Published version at: http://dx.doi.org/10.1002/jgrd.50179

To link to this article DOI: http://dx.doi.org/10.1002/jgrd.50179

Publisher: American Geophysical Union

All outputs in CentAUR are protected by Intellectual Property Rights law, including copyright law. Copyright and IPR is retained by the creators or other copyright holders. Terms and conditions for use of this material are defined in the End User Agreement.

www.reading.ac.uk/centaur 
Central Archive at the University of Reading

Reading's research outputs online 


\title{
Identification and ranking of extraordinary rainfall events over Northwest Italy: The role of Atlantic moisture
}

\author{
Joaquim G. Pinto, ${ }^{1}$ Sven Ulbrich, ${ }^{1}$ Antonio Parodi, ${ }^{2}$ Roberto Rudari, ${ }^{2}$ Giorgio Boni, ${ }^{2}$ \\ and Uwe Ulbrich ${ }^{3}$
}

Received 19 July 2012; revised 10 January 2013; accepted 10 January 2013; published 1 March 2013.

[1] An objective identification and ranking of extraordinary rainfall events for Northwest Italy is established using time series of annual precipitation maxima for 1938-2002 at over 200 stations. Rainfall annual maxima are considered for five reference durations $(1,3,6$, 12 , and $24 \mathrm{~h}$ ). In a first step, a day is classified as an extraordinary rainfall day when a regional threshold calculated on the basis of a two-components extreme value distribution is exceeded for at least one of the stations. Second, a clustering procedure taking into account the different rainfall durations is applied to the identified 163 events. Third, a division into six clusters is chosen using Ward's distance criteria. It is found that two of these clusters include the seven strongest events as quantified from a newly developed measure of intensity which combines rainfall intensities and spatial extension. Two other clusters include the weakest $72 \%$ historical events. The obtained clusters are analyzed in terms of typical synoptic characteristics. The two top clusters are characterized by strong and persistent upper air troughs inducing not only moisture advection from the North Atlantic into the Western Mediterranean but also strong northward flow towards the southern Alpine ranges. Humidity transports from the North Atlantic are less important for the weaker clusters. We conclude that moisture advection from the North Atlantic plays a relevant role in the magnitude of the extraordinary events over Northwest Italy.

Citation: Pinto, J. G., S. Ulbrich, A. Parodi, R. Rudari, G. Boni, and U. Ulbrich (2013), Identification and ranking of extraordinary rainfall events over Northwest Italy: The role of Atlantic moisture, J. Geophys. Res. Atmos., 118, 2085-2097, doi:10.1002/jgrd.50179.

\section{Introduction}

[2] The characteristics of climate in the Mediterranean Region (MR) include a frequent occurrence of extreme rainfall events on a variety of space and time scales [Siccardi, 1996], eventually leading to floods. Extreme rainfall in the Western MR is generally related to both local conditions and the occurrence of specific regional large-scale circulation patterns [e.g., Rudari et al., 2005; Nuissier et al., 2008]. They are typically triggered by lee cyclogenesis in the same region [e.g., Buzzi and Tibaldi, 1978]. This process contributes to focus the precipitation over a particular area by inducing temporal stable flow towards the mountains ranges. The role of large-scale meteorological conditions, e.g., in terms of moisture advection from the North Atlantic (NA) into the MR, has been demonstrated in several case studies: for

\footnotetext{
All Supporting Information may be found in the online version of this article.

${ }^{1}$ Institute for Geophysics and Meteorology, University of Cologne, Cologne, Germany.

${ }^{2}$ CIMA Research Foundation, Savona, Italy.

${ }^{3}$ Institute for Meteorology, Freie Universität Berlin, Berlin, Germany.

Corresponding author: J. G. Pinto, Institute for Geophysics and Meteorology, University of Cologne, Kerpener Str. 13, 50923 Cologne, Germany. (jpinto@meteo.uni-koeln.de)

(C)2013. American Geophysical Union. All Rights Reserved. 2169-897X/13/10.1002/jgrd.50179
}

example, Cassardo et al. [2001] and Turato et al. [2004] described the relevance of moisture sources over the NA to the November 2000 event in Piemonte. Further, Winschall et al. [2012] documented that evaporation over the NA was the main moisture source for the November 2002 event over North Italy. However, the NA basin is a moisture source not only for single extreme events; Rudari et al. [2005] suggested that there is significant moisture advection from the NA basin into the Western MR specifically for the upper percentiles of heavy precipitation events. This was recently generalized by Winschall et al. [2012], who found evidence that moisture advection from the NA basin is important for heavy precipitation events south of the Alps. Note that an upstream influence from the NA has also been shown for events over the Eastern MR [e.g., Krichak et al., 2004]. Martius et al. [2006] have stressed the link between the presence of upper-level troughs (Potential Vorticitystructures) over Western Europe and high precipitation events on the alpine region as a further mechanism for a large-scale trigger. Such structures had been recognized for case studies [e.g., Massacand et al., 1998; Winschall et al., 2012].

[3] Extreme precipitation events occur preferentially on the onwind slopes of mountain ranges [e.g., Llasat et al., 2005; Milelli et al., 2006]. Accordingly, some alpine regions experience a much higher frequency of extreme precipitation events than other locations in central Europe [Frei and Schär, 1998]. On the other hand, the influence of orography 
also includes downwind sheltering [e.g., Smith and Barstad, 2004]. Complex orography thus leads to a strong spatial and temporal heterogeneity in terms of precipitation distribution [e.g., Frei and Schär, 1998]. Numerous studies have been performed on rainfall events in the Western MR, in particular for the orographically structured areas of northeastern Spain, Southern France, and Northern Italy [e.g., Llasat et al., 2005; Nuissier et al., 2008; Ricard et al., 2012]. Such effects complicate estimations of the hydrometeorological consequences (e.g., river discharge values and subsequent floods). Both the spatial and temporal distribution of rainfall intensities and extension of the events must be considered in order to interpret adequately the integral effects of precipitation in terms of flooding. Ranking heavy precipitation events is still an open problem, as it is influenced by multiple time and spatial scales that assume different importance depending on the application envisaged for the analysis [Muller et al., 2009].

[4] Boni et al. [2008] developed a methodology to map the spatial distribution of rainfall annual maxima (RAM), as defined by Boni et al. [2006], in a mountainous environment. Boni et al. [2006, 2008] used a rainfall database featuring precipitation records of over 200 stations for a period of 60 years, which they analyzed in terms of spatial patterns and intensity distributions of RAM for different time windows (from 1 to $24 \mathrm{~h}$ ). They identified different dominant seasons for RAM recorded on different durations on the basis of their statistical characteristics and suggested that meteorological conditions may explain these effects. In Piemonte, for example, summer is dominated by the rather short time windows ( 1 and $3 \mathrm{~h}$ RAM), while in autumn the $24 \mathrm{~h}$ RAM is prevalent.

[5] Previous analysis of extreme precipitation events has included methods for the classification of events [e.g., Llasat, 2001; Casas et al., 2004] and different possibilities for clustering them [e.g., Rigo and Llasat, 2007; Nuissier et al., 2008]. However, these methods do not simultaneously take the spatial extension and the different rainfall time scales of the events into account. The methodology applied in the present study is designed to overcome this limitation by capturing both local intensities at different (daily to subdaily) aggregation time scales and extension of the affected area. It is thus performing a classification independent of large-scale (synoptic) meteorological features or patterns, restricting the input data to local rainfall amounts at individual stations in the areas considered.

[6] While Rudari et al. [2005] compared the synoptic characteristics of non-extreme with extreme rainfall events, the synoptic characterization refers to the clusters. Still, we restrict ourselves to the analysis of extraordinary $24 \mathrm{~h}$ rainfall extremes. Additionally, a ranking is established again taking into account both the events' local intensity and spatial extent. Thus, the current study offers a new way to classify and quantify events, focusing on Northwest Italy, encompassing the regions Liguria, Piemonte, Ticino, and Valle d'Aosta.

[7] The structure of the paper is as follows: A short description of the data used is given in section 2, while section 3 describes the methodologies used. The results of the objective classification of extreme events are presented in section 4. In section 5, the synoptic evolution of the events is analyzed and classified, with special attention given to the identification of moisture sources exterior to the MR. The final section presents the conclusions.

\section{Data}

[8] Rainfall annual maxima (RAM) from rain gauge stations over Northwest Italy are available in a database for five different reference durations $(1,3,6,12$, and $24 \mathrm{~h})$. They are based on measurements of a dense rain gauge network in Liguria, Piemonte, and Valle d'Aosta (Figure 1), made by different offices of the Italian National Hydrological Service (Servizio Idrografico e Mareografico Nazionale) and more recently the regional offices for the protection of the environment, which are now in charge of maintaining the gauging network. The present RAM database is an extension of the database used in Boni et al. [2006] for the target region: more recently recorded values have been added, and data for the Valle d'Aosta region have been integrated. However, stations with a short record history were removed. The database used encompasses the period from 1930 to 2005 and includes a variable number of stations (Figure S1, auxiliary material). ${ }^{1}$ Details on quality control of the data and the improvements relative to Boni et al. [2006] are presented in auxiliary material A. The period used for classification is 1938-2002. The database was produced from an original data set consisting of complete high temporal resolution rainfall records $(10 \mathrm{~min}$ for the earliest records and $5 \mathrm{~min}$ for the more recent ones) using moving time windows to identify the respective RAM at different durations. Unfortunately, only parts of the original data set are available, too small to be used for an extensive analysis on extremes. We could use, however, a set of daily precipitation data for selected stations (242 stations for the period 1957-1987 and 299 stations for 1990-2002). These daily data are used to quantify the impact of limitations of RAM database regarding the number and spatial extension of extraordinary events.

[9] For the diagnoses of the atmospheric conditions leading to the rainfall events, we use data from the European Centre for Medium-Range Weather Forecast ERA40 data set [Uppala et al., 2005] in a resolution of $1.125^{\circ} \times 1.125^{\circ}$. The data are available for the period 1957-2002 for every $6 \mathrm{~h}$. Synoptic information was also taken from the "Europäischer Wetterbericht" (available under http://www. dwd-shop.de/details/0095d.html) and "Berliner Wetterkarte," (available under http://wkserv.met.fu-berlin.de/), two daily meteorological reports for central Europe from the German Weather Service and from the Freie Universität Berlin, respectively.

\section{Methodology}

\subsection{Event Definition}

[10] RAM events at individual stations in Northwest Italy are well described by the Two-Components Extreme Value distribution (TCEV) introduced by Rossi et al. [1984], which is a distribution derived by a mixture of two Gumbel distributions, one describing "ordinary" maxima and the second describing the "extraordinary" ones. Based on this distribution, Boni et al. [2006] proposed an objective way for separating ordinary and extraordinary values which show distinct statistical behavior. The algorithm developed by Boni et al. [2006] makes use of the dimensionless parameter $K t$. $K t$ is defined as the recorded RAM values made dimensionless with the (station specific) expected value (the mean RAM) for that duration ( $1 \mathrm{~h}, 3 \mathrm{~h}, 6 \mathrm{~h}, 12 \mathrm{~h}$, and $24 \mathrm{~h}$ ) [Boni 

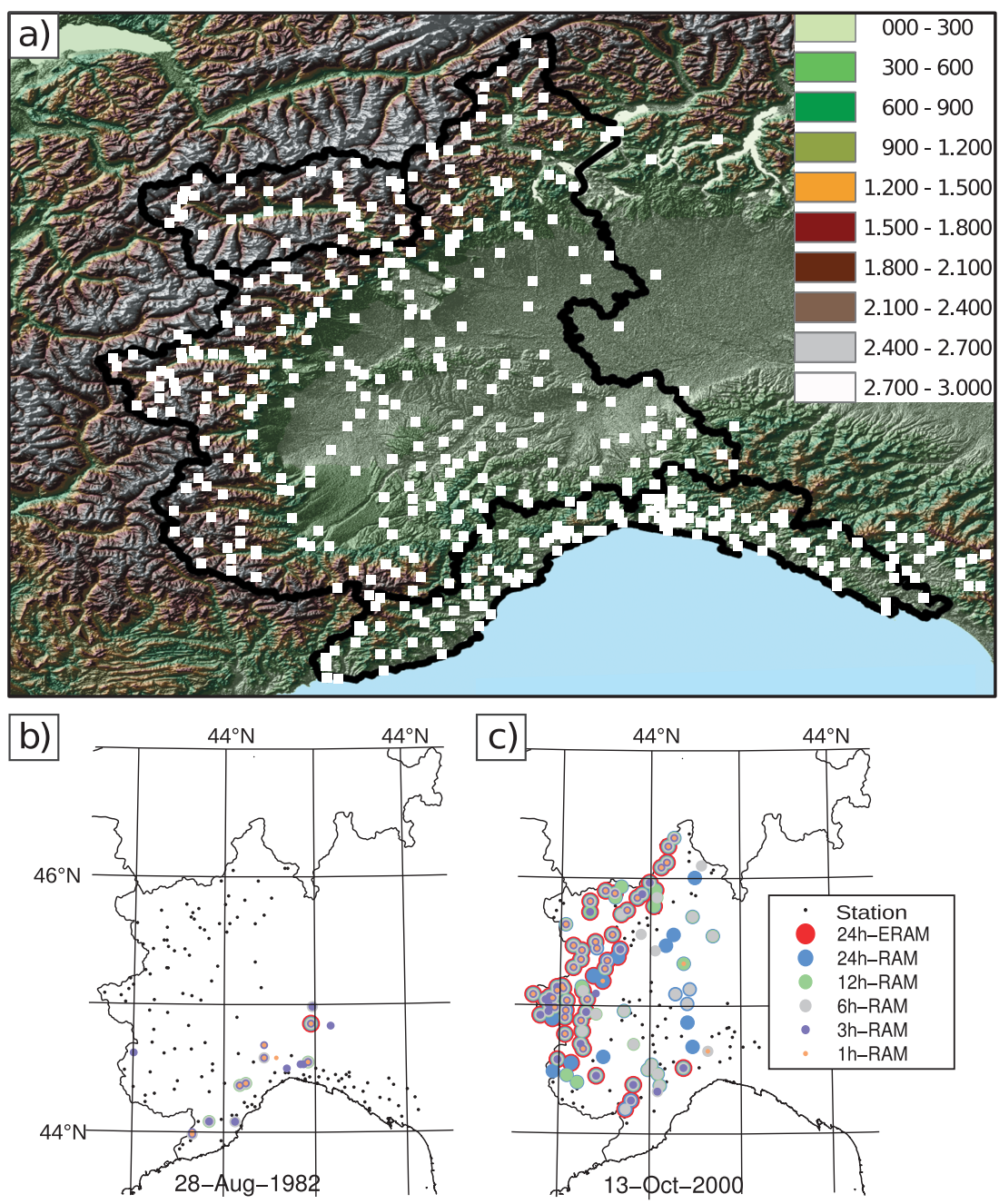

Figure 1. (a) Orography over Northwest Italy. Different height levels are shaded with colors. Liguria, Piemonte, and Valle d'Aosta are delimited with black contours. The location of stations are marked with white squares. (b) RAMs for different durations for 28 August 1982. The stations measuring a RAM are marked with different colours. Each colour represents a different duration: $24 \mathrm{~h}$ : blue (extraordinary: red); $12 \mathrm{~h}$ : green; $6 \mathrm{~h}$ : gray; $3 \mathrm{~h}$ : purple; $1 \mathrm{~h}$ : orange. Stations measuring in 1982 but not experiencing a RAM are marked with black dots. (c) as in Figure 1 b but for 13 October 2000.

et al., 2006, 2008]. The expected value is approximated by the sample mean of recorded RAM. Some authors [e.g., Svenisson et al., 2001] have criticized this approximation. However, Boni et al. [2008] provided evidence that using the RAM sample mean for $K t$ computation introduces only negligible estimation errors when the sample size of time series is large enough $(n>20)$.

[11] For TCEV, the expected value corresponds in average to a 2.9 year return period. This normalization has the main objective of obtaining values at the stations comparable to each other. A threshold $K t^{\prime}$ valid for statistically homogeneous regions [see Beran et al., 1986] is determined for each region and for each of the five durations [cf. Boni et al., 2006], allowing the identification of extraordinary RAMs when the relation $K t \geq K t^{\prime}$ applies for the correspondent time scale. Note that a statistically homogeneous region is defined based on the homogeneity of the station data probability density function in terms of coefficient of variation and higher order moments (i.e., skewness and kurtosis), as performed in previous methodologies [e.g., Gabriele and Arnell, 1991]

[12] Following this approach, we focus solely on events with an extraordinary character for at least one of the recording stations: a rainfall event must feature one extraordinary $24 \mathrm{~h} \mathrm{RAM}$ on at least one of the stations to be classified as extraordinary event. This choice is mathematical (as it stems from the TCEV), but according to Boni et al. [2006], these events are causing strong hydrometeorological effects on different time scales from 1 to $24 \mathrm{~h}$. Once a date is identified, RAMs (ordinary and extraordinary) for each duration are searched for the same date (and subsequent days containing at least one extraordinary $24 \mathrm{~h}$ RAM, with a maximum of 3 days). This information is included in the characterization of the identified extraordinary event, which, from now on, will be referred to simply as one "event." A total of 163 events are identified in the period of 1938 to 2002 . They 
are characterized by the information of the number of RAMs for each time window, their spatial distribution, and rainfall intensity (expressed in terms of $K t$ values).

[13] Since the database records contain only one $24 \mathrm{~h}$ RAM for each station per year, some important events may be missed. In particular, this can happen if a specific station has more than one extraordinary $K t$ value in a single calendar year. Comparing RAM data and a complete series of daily rainfall totals from the subperiod 1990-2002, it was found that the probability of occurrence of more than one extraordinary rainfall event within a year at single station is less than $10 \%$ (not shown). There was also no evidence for an effect on the intensity and/or spatial extension of the events as discussed in the following section of this paper. The effect of seasonality was not regarded because there is basically only one wet season in this area. Thus, the considered RAMs are season independent. Unfortunately, RAM data are not available for hydrological years but only for calendar years. Thus, the RAM database is found to be a sufficient basis for a classification of the events and for the subsequent investigation of the triggering synoptic patterns.

\subsection{Spatial Extension of Events and Correction of Station Density Bias}

[14] All stations experiencing a RAM of any duration at an event date contribute to the spatial extension of that event. All durations are considered separately, so that a station can be included in up to five rain areas assigned to the five different durations for the same event. Events can be visualized by plotting maps showing the affected stations, indicating RAM for all five durations at all available gauging stations (cf. examples in Figures $1 \mathrm{~b}$ and 1c). This enables a fast evaluation of the events, both in terms of their extension and the affected temporal scales. A relevant problem in characterizing the spatial extension of the events is related with the change in the number of gauge stations over the years (Figure S1, Figures $1 \mathrm{~b}$ and $1 \mathrm{c}$ ). This fact can introduce biases in the spatial extension of the events and thus in their ranking: We dealt with this by taking for each station the distance to neighboring stations during that year into account, when integrating Kts for a particular event. More details can be found in auxiliary material B. The result of the methodology is an index named Rescaled Event Intensity (REI), which is given for an event by $\operatorname{REI}_{\text {event }}(d)=\sum_{i=1}^{n} K t_{i}(d) \cdot r_{m_{i}}$, where $n$ is the number of stations that recorded any rainfall during the event, $d$ the five time windows ( 1 to $24 \mathrm{~h}$ ), and $r_{m}$ a calculated representative radius for each station.

\subsection{Cluster Analysis}

[15] A cluster analysis is applied in order to combine groups of data with similar characteristics based on REI for different time scales. In this work, we apply a hierarchical clustering method on our REI data set. Hierarchical clustering is an iterative process in which the number of clusters is successively decreased. Thus, it provides a multilevel hierarchy, where clusters at one level are joined as clusters at the next higher level (like a tree). The method has the advantage of visualizing the combination of the observations to form clusters, which facilitate the choice on the number of clusters to be retained [Ramos, 2001]. This characteristic is thus helpful to identify the optimum number of clusters. The distances between clusters are computed using the Ward distance, which is defined as the sum of squares between the two clusters added over all the variables [Ward, 1963]. This measure is known for producing large clusters, which are useful to obtain statistically significant results. At any step of aggregation, the within-cluster sum of squares is minimized over all possible merges between two clusters from the previous generation. This method tends to join clusters with a small size and, therefore, to produce clusters with similar number of observations. The cluster mean rainfall intensity is computed based on REI (cf. supplementary material) for all events of that cluster.

\subsection{Synoptic Characterization}

[16] The large-scale conditions associated with the extreme events are analyzed based on weather charts and reanalysis data. The objective is to detect possible particularities on the large-scale atmospheric conditions, moisture transport, and moisture sources. With this aim, low-level moisture advection and convergence (at $850 \mathrm{hPa}$ ) is computed from ERA-40 data, together with three-dimensional backward trajectories starting at 850 and $700 \mathrm{hPa}$. The trajectory package [after Methven, 1997] is based on 3-D wind components. The humidity of the parcel is the value from the reanalysis for that time frame and that vertical level. The backward trajectories indicate the path of air masses associated with the precipitation events. The method has been extensively tested [e.g., Methven et al., 2001; Fragoso et al., 2012], and the obtained results are compared with other approaches for case studies [e.g., Turato et al., 2004]. Further, $500 \mathrm{hPa}$ geopotential height fields and mean sea level pressure (MSLP) are considered to describe the large-scale conditions associated with the extreme events.

[17] Further, cyclone tracks associated with the events are obtained using an algorithm originally developed by Murray and Simmonds [1991], adapted for the Northern Hemisphere/ MR cyclone characteristics [Pinto et al., 2005]. Cyclones are identified using a proxy of their relative geostrophic vorticity, which is particularly adequate for the shallow systems typical of the MR region. Further details can be found, e.g., in Pinto et al. [2005].

\section{Clustering and Ranking of Extreme Rainfall Maxima}

[18] The obtained 163 events are now characterized in terms of their hydrological characteristics using the hierarchical clustering approach based on REI. The objectives are to (a) group and (b) rank the events.

[19] A hierarchical cluster analysis is performed on the retrieved events. The database is searched for subsets with similar REI considering a five-dimensional vector with one component for each of the five available time windows. This concurrent information is used for the characterization of the severity of the event. Six clusters are obtained, as this number allows the best separation between the different clusters covering the whole spectrum of events (cf. Figure S3). A larger number of clusters would lead to a very small distance between some of the groups and thus to little added information (the next partition would be within the cluster which includes the weakest events). On the other hand, a 
Table 1. Per Cluster, the Number of Events, Number of ERAM Stations, Number of $24 \mathrm{~h}$ RAM, and Percentage of RAM in Terms of the Reporting Stations for Each Time Window

\begin{tabular}{lllllll}
\hline \multicolumn{1}{c}{ Cluster } & \multicolumn{1}{c}{ I } & \multicolumn{1}{c}{ II } & \multicolumn{1}{c}{ III } & \multicolumn{1}{c}{ VI } & \multicolumn{1}{c}{ V } & \multicolumn{1}{c}{ VI } \\
\hline Nr. Events & $2(2)$ & $5(3)$ & $18(14)$ & $14(11)$ & $33(23)$ & $91(68)$ \\
Nr. ERAM stat. & 48 & 17.2 & 8.6 & 3.9 & 2.1 & 1.4 \\
Nr. 24 h RAM stat. & 95.5 & 72.4 & 55.7 & 25.6 & 24.3 & 5.2 \\
\% stat. 24 h RAM & 47 & 43 & 37 & 17 & 18 & 4 \\
\% stat. 12 h RAM & 40 & 43 & 29 & 19 & 13 & 3 \\
\% stat. 6 h RAM & 38 & 34 & 21 & 19 & 10 & 3 \\
\% stat. 3 h RAM & 28 & 24 & 17 & 18 & 7 & 3 \\
\% stat. 1 h RAM & 18 & 16 & 10 & 15 & 4 & 3 \\
\hline
\end{tabular}

smaller number of clusters would lead to a strong reduction in the information: for example, with four clusters the present clusters I/II and III/IV would be joined. The number of events per cluster is given in Table 1 .
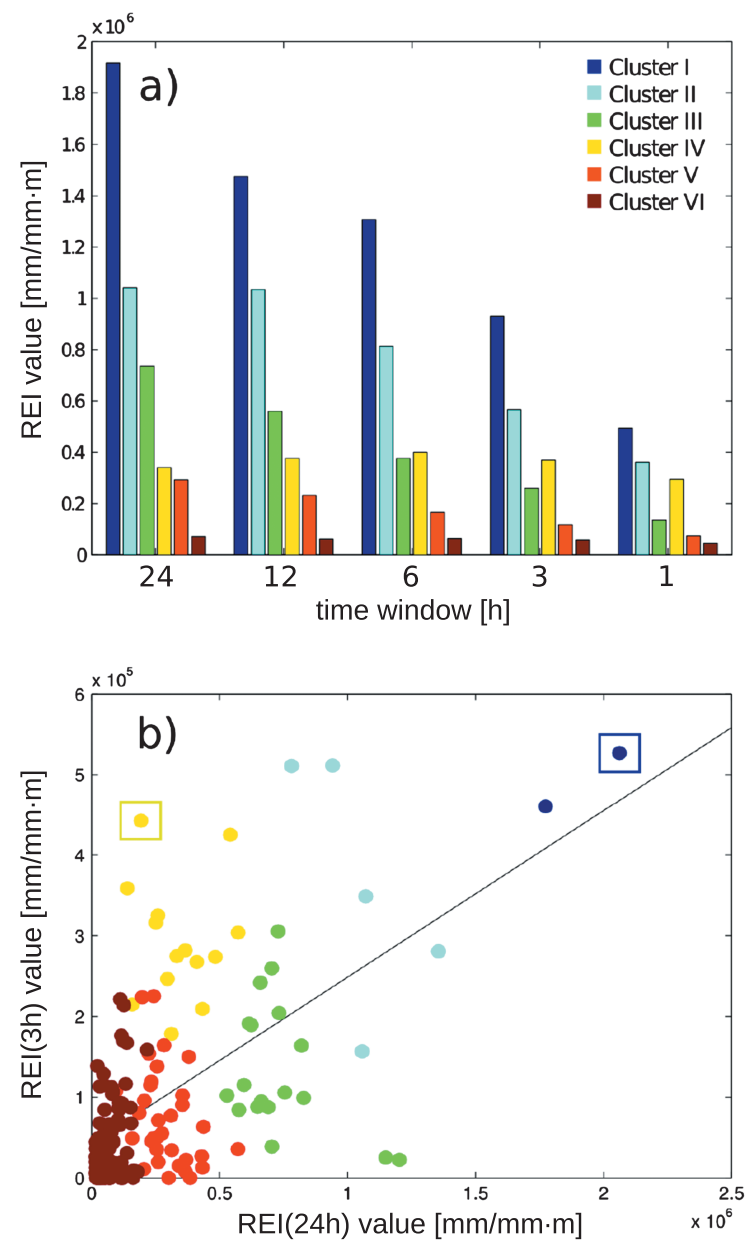

Figure 2. (a) Mean intensity distribution over different time scales for each cluster. The different durations (1, 3, $6,12,24 \mathrm{~h})$ are shown on the $x$ axis. The intensity ( $y$ axis) is given as radius* $\left.K t ; \mathrm{mm} / \mathrm{mm}^{*} \mathrm{~m}\right)$. Different clusters are depicted in color. (b) Scatter plot displaying the relationship between $24 \mathrm{~h}$ REI ( $x$ axis) and $3 \mathrm{~h}$ REI for each event. The color scale for the clusters is the same as in Figure $2 \mathrm{a}$. The circles marked with squares correspond to the events 13 October 2000 (blue) and 21 September 1981 (dark yellow) described in section 5.2 .
[20] Cluster I contains the most intense events in terms of REI based on the $24 \mathrm{~h}$ sums, and cluster VI the weakest ones (Figure 2a). It is interesting to compare the intensities of these $24 \mathrm{~h}$ REI with $3 \mathrm{~h}$ REI (cf. Figure 2b) as an example: the separation between clusters III and IV is clear and can basically be explained by the values of $3 \mathrm{~h}$ REI. The $6 \mathrm{~h}$ and $1 \mathrm{~h}$ REI comprise similar values to the $3 \mathrm{~h}$ component (not shown). For these two clusters, the same ranks apply on each of the five considered rainfall durations (Figure $2 \mathrm{a}$ only includes $24 \mathrm{~h}$ and $3 \mathrm{~h}$ duration). Clusters III and IV have about the same loadings for $24 \mathrm{~h}$ but are clearly distinct with respect to short durations (see scatter plot in Figure 2b, with REI of $3 \mathrm{~h}$ as an example).

[21] Table 1 includes information on the average numbers of stations with an extraordinary rainfall annual maximum (ERAM), with extraordinary and/or ordinary rainfall annual maximum (RAM) for different time windows. Results show that the number of stations with ERAM decreases with the order number of clusters. A similar result is found with respect to all RAMs. The percentage of stations with RAM is a measure of the size of the affected area. The percentage of stations (cf. Table 1) experiencing a $24 \mathrm{~h}$ RAM decreases continuously from cluster I (47\%) to cluster VI (4\%), with the exception of cluster IV (17\%), which has a slightly smaller value than cluster V (18\%). For the other time windows (1-12 h), a monotonous decrease is also present, except that the affected percentage of stations for the durations $1 \mathrm{~h}$ and $3 \mathrm{~h}$ is higher for cluster IV than for cluster III. These results support our working hypothesis that very intense events are caused by a combination of large-scale (typically weaker but longer precipitation events) and convective precipitation (short but intense precipitation events). With decreasing intensity, there is the possibility of the events to be either (a) more convective (like cluster VI events) or to be (b) more large-scale precipitation forced (like cluster III events).

[22] The seasonal distribution of events per month and cluster is shown in Table S1. All events for clusters I/II and $54 \%$ of all 163 events occur in autumn. This is also the case for most of the events in cluster III, even though five events occur outside autumn. Regarding cluster IV, events are biased towards late summer/early autumn compared to cluster III. The two weaker clusters show a broader spectrum, with events occurring in spring and winter (each month) for cluster V (cluster VI).

[23] Based on the value of the $24 \mathrm{~h}$ REI per event, a clear ranking for all 163 events is given. The top 20 are listed in Table S2. Sixteen events occurred in autumn (September to November), clearly indicating that the particular largescale atmospheric conditions in autumn are instrumental to the frequency of extreme events occurring over the study area for this season. This is in agreement with previous works and with the observed seasonality of the top ranking extreme events [e.g., Rudari et al., 2005].

\section{Synoptic Characterization of Events}

[24] In this section, we examine the large-scale conditions associated with the extreme rainfall events. The inspection of synoptic weather charts for each of the top 50 extreme rainfall events showed that cyclones were present over the region in each case (not shown; data only considered starting 1955, as weather charts are unfortunately not available 
before that date). Such local cyclones are, however, very shallow in some cases.

\subsection{Characterization of the Six Clusters}

[25] We now characterize meteorologically the six clusters by identifying the typical synoptic conditions for the ele-

Table 2. Summary of Cluster Characterization

\begin{tabular}{ll}
\hline Cluster & Cluster characteristics \\
\hline I & $\begin{array}{l}\text { very high intensity; very large area affected; strong humidity } \\
\text { flux; long and very humid trajectories; area of their origin is } \\
\text { located furthest west of all clusters } \\
\text { high intensity; large area affected; same properties as cluster I } \\
\text { but less pronounced } \\
\text { moderate intensity; large-scale rainfall; large area affected; } \\
\text { moderate humidity flux; long and comparatively dry } \\
\text { trajectories } \\
\text { moderate intensity; convective type; moderate area affected; } \\
\text { moderate humidity flux into the Mediterranean area; short } \\
\text { and very humid trajectories } \\
\text { low intensity; moderate area affected; weak humidity flux; } \\
\text { short and comparatively dry trajectories } \\
\text { lowest intensity; small area affected; weakest humidity flux; } \\
\text { shortest and comparatively very dry trajectories }\end{array}$ \\
VI &
\end{tabular}
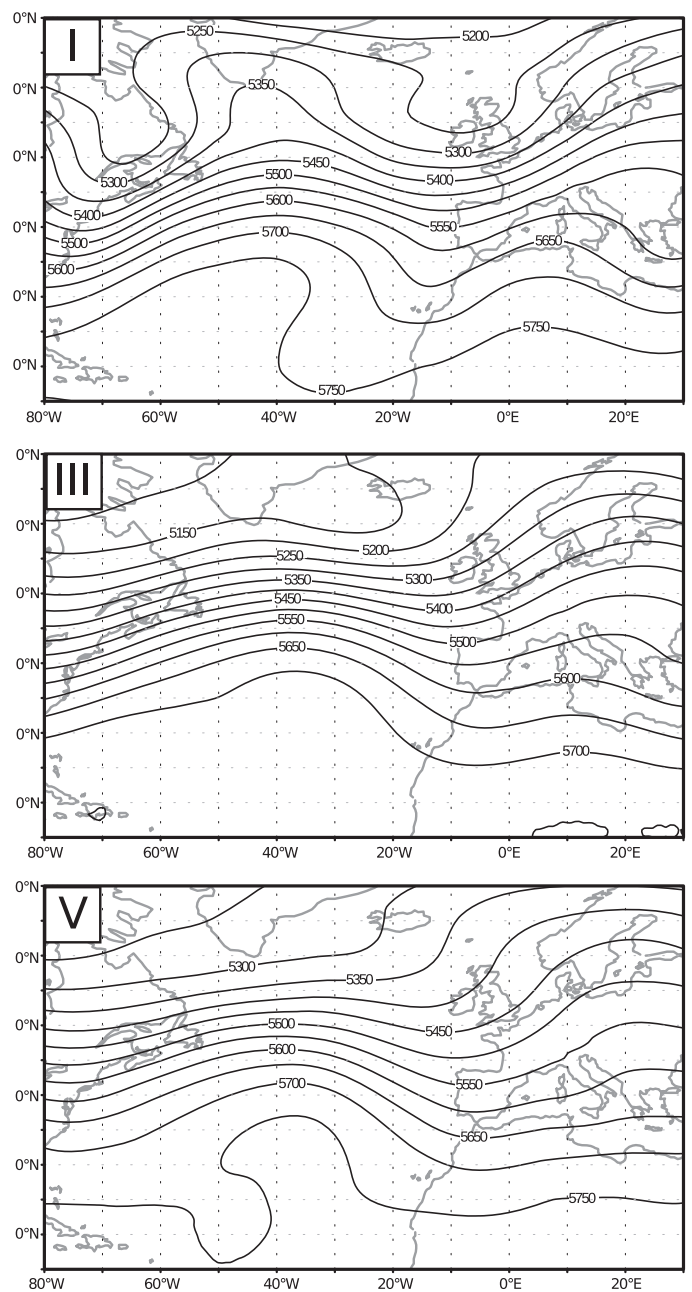

ments of each cluster and comparing them to other clusters. The number of investigated events is limited to a total of 121 due to the data availability (see Table 1). The typical characteristics of the six clusters are summarized in Table 2. First, the average numbers of stations with an ERAM and with RAM are generally decreasing with the order number of clusters (Table 1).

[26] Midtropospheric flow conditions, moisture advection, and backward trajectories for each cluster are shown in Figures 3, 4, and 5. Typically, a large-scale steering low associated with an upper air trough is present near the British Isles/Gulf of Biscay. Their intensity, persistence, and exact location, however, do change from cluster to cluster. For the top ranking clusters, the upper air trough is typically not only more intense (see Figure 3 ) but also more persistent: While for cluster I the trough is quasi-stationary for about 7 days, this value decreases progressively to $1-2$ days for cluster VI (not shown). This clearly indicates that the large-scale conditions associated with the top clusters clearly contribute to sustained moisture advection into the Western MR. Further, the 3 day humidity flux (Figure 4) exhibits a maximum over the NA but with different location and intensity depending on the cluster. While for top clusters (I and II)
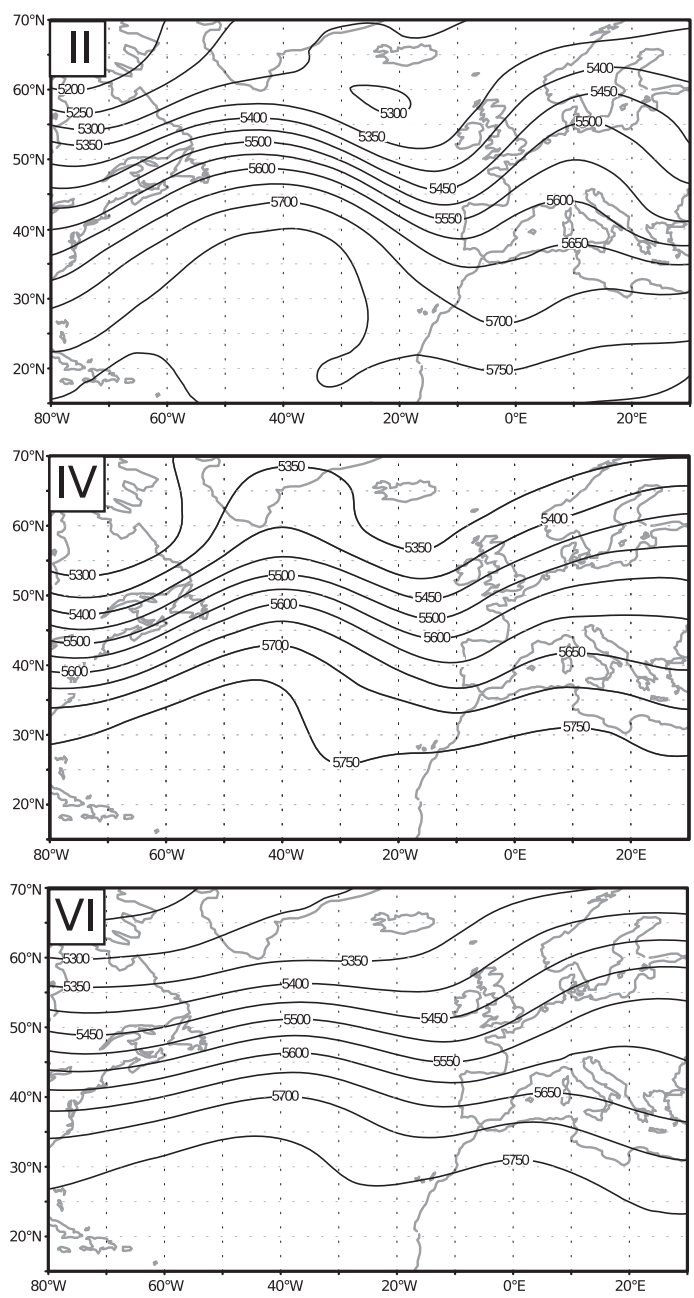

Figure 3. mean $500 \mathrm{hPa}$ geopotential height field [gpdm] for each cluster. The average period starts 3 days before the event and ends at the first day of the event. The roman numerals correspond to the clusters. 

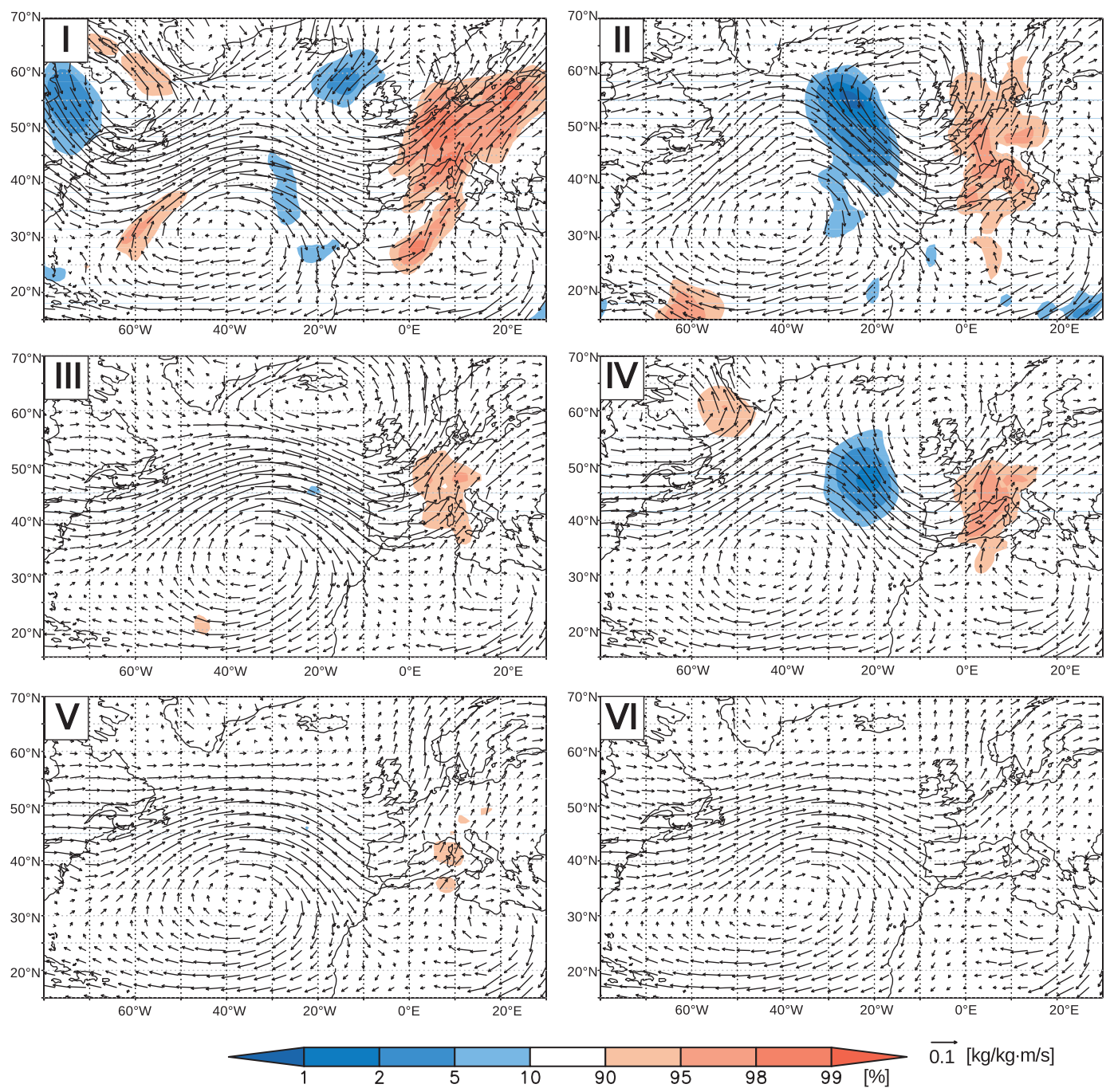

Figure 4. Three-day mean humidity advection $[\mathrm{kg} / \mathrm{kg} \cdot \mathrm{m} / \mathrm{s}]$ for each cluster. The average period starts 3 days before the event and ends at the first day of the event. The roman numerals correspond to the clusters.

the trough extends far south, thus enabling stronger moisture advection into the MR, it is not so pronounced for the other clusters. In particular, the top clusters I and II have the largest 3 day mean humidity advection. Figure 4 also shows significances for the meridional component of moisture advection, the most relevant in this case to induce enhanced precipitation in the southern Alpine slopes. Results show that a widespread significant strong northward advection (red areas) is detected to the first four clusters within the Western MR, very strong for clusters I and II, and somewhat weaker for clusters III and IV. Finally, the starting points of the 3 day backward trajectories are shown as a "trajectory source areas density" for all events of a cluster (Figure 5). Again, a clear difference is observed between the clusters. The weakest clusters (V and VI) feature starting points with a higher probability in the MR, while the top clusters show a significant percentage of trajectories starting over the NA Basin, some as far as Newfoundland.

[27] Based on the analysis of the 163 events in our database and the ranking classification, we found evidence for an influence of NA in terms of moisture advection from the NA Basin towards the Western MR shortly before the event particularly for the most highly ranked events. This is in agreement with the recent study by Winschall et al. [2012], who analyzed the impact of the evaporation hot spots over the eastern NA for heavy precipitation events over southern Alpine region based on a 10 year climatology. The lower ranked events are less influenced from the NA and thus may be considered more "regional" events. Moisture incoming from the NA is, however, not only relevant for extreme events. Drumond et al. [2011] and Nieto et al. [2010] provided evidence that the subtropical NA is a secondary climatological moisture source for the Western MR.

\subsection{Case Studies}

[28] We now analyze the top 20 events. Two representative cases are discussed in detail: The first case (13-15.10.2000) is a member of cluster I and the top ranking event in the database, while the second case (21.09.1981) is a member of cluster IV. This latter cluster shows the strongest differences from cluster I in terms of the relative REI values in the 

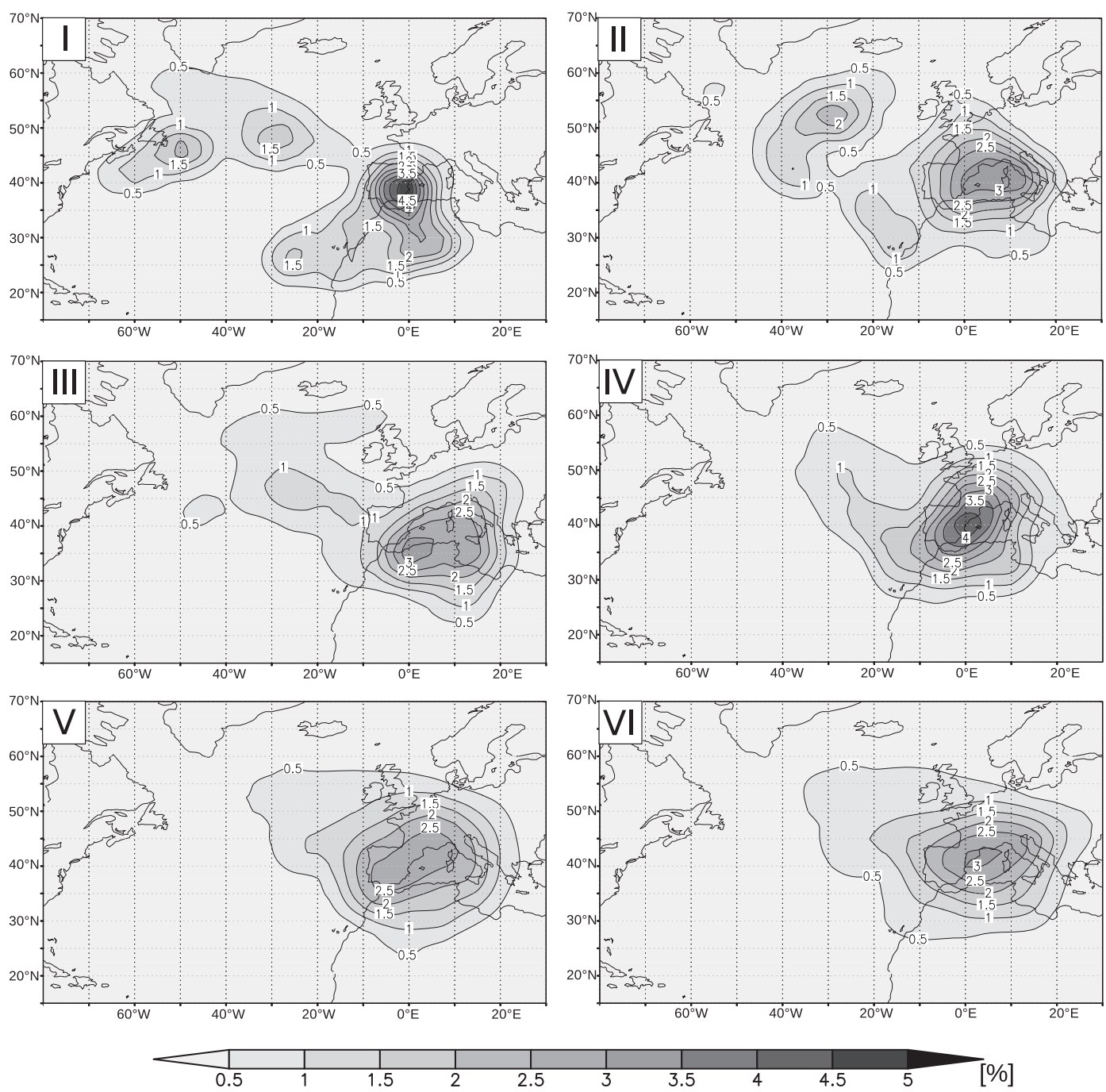

Figure 5. Spatial density of the starting locations of 3 day backward trajectories for each cluster. The values are given as percentage of total number of trajectories. The trajectories were started at 1200 UTC at the day of occurrence of the event, the day before, and 2 days before. The roman numerals correspond to the clusters.

different time windows particularly on the $1 \mathrm{~h}$ time window. A synopsis of the characteristics of all 20 events follows.

[29] The event on 13-15 October 2000 is the top ranked event in our database (cf. Table S2). It is a prime candidate for detailed evaluation, also because it has been investigated previously as case study [e.g., Gabella and Mantonvani, 2001; Cassardo et al., 2001; Turato et al., 2004]. Extraordinary rainfall amounts were measured all 3 days predominantly in the Alpine region (cf. Figure 6a). Maximum precipitation was recorded at single stations reaching $134 \mathrm{~mm}, 403.8 \mathrm{~mm}$, and $406.4 \mathrm{~mm}$ on 13,14 , and 15 October 2000, respectively. The highest 3 day sum of precipitation was $706 \mathrm{~mm}$ at Bonganco-Pizanco (upper Po Valley). This event shows most of the REI on the $24 \mathrm{~h}$ basis, decreasing steadily for $12 \mathrm{~h}, 6 \mathrm{~h}, 3 \mathrm{~h}$, and $1 \mathrm{~h}$ REI (cf. Figure 6b). The severe precipitation event led to a flood in the Upper Po Valley during the following days. The extreme event was locally induced by a shallow cyclone ("Josefine", marked "1" in Figure 7). Preliminary tropical storm "Leslie" tracked northward along the North American coast (blue line in Figure 7d) bringing a huge amount of moisture into the extratropics (compare Pinto et al. [2001] and Turato et al. [2004]). During 8-9 October, the tropical storm "Leslie" underwent extratropical transition, whose remnants then moved eastward towards the British Isles as extratropical cyclone "Imke" (marked " 2 " in Figure 7a). The 3 day mean humidity flux for the period 10-13 October (Figure 6c) shows a very intense flow over the NA Basin towards the MR. The contribution of such moisture advection from the NA Ocean to the event's intensities (and thus to the occurrence of subsequent local floods) has been demonstrated in case studies of extreme events in this area by evaporation/ precipitation models [e.g., Reale et al., 2001; Turato et al., 2004; Winschall et al., 2012]. In fact, half of the 3 day backward trajectories starting 12 October go back to an area close to Canada (cf. Figure 8a), where the tropical storm "Leslie" was located on 9-10 October. The trajectories are restricted to 3 days because the humidity is not directly traced by the applied methodology. Further, these trajectories feature an unusually high amount of specific humidity (for such latitudes), documenting the high humidity in the air mass associated with the remnants of the tropical storm (now cyclone 

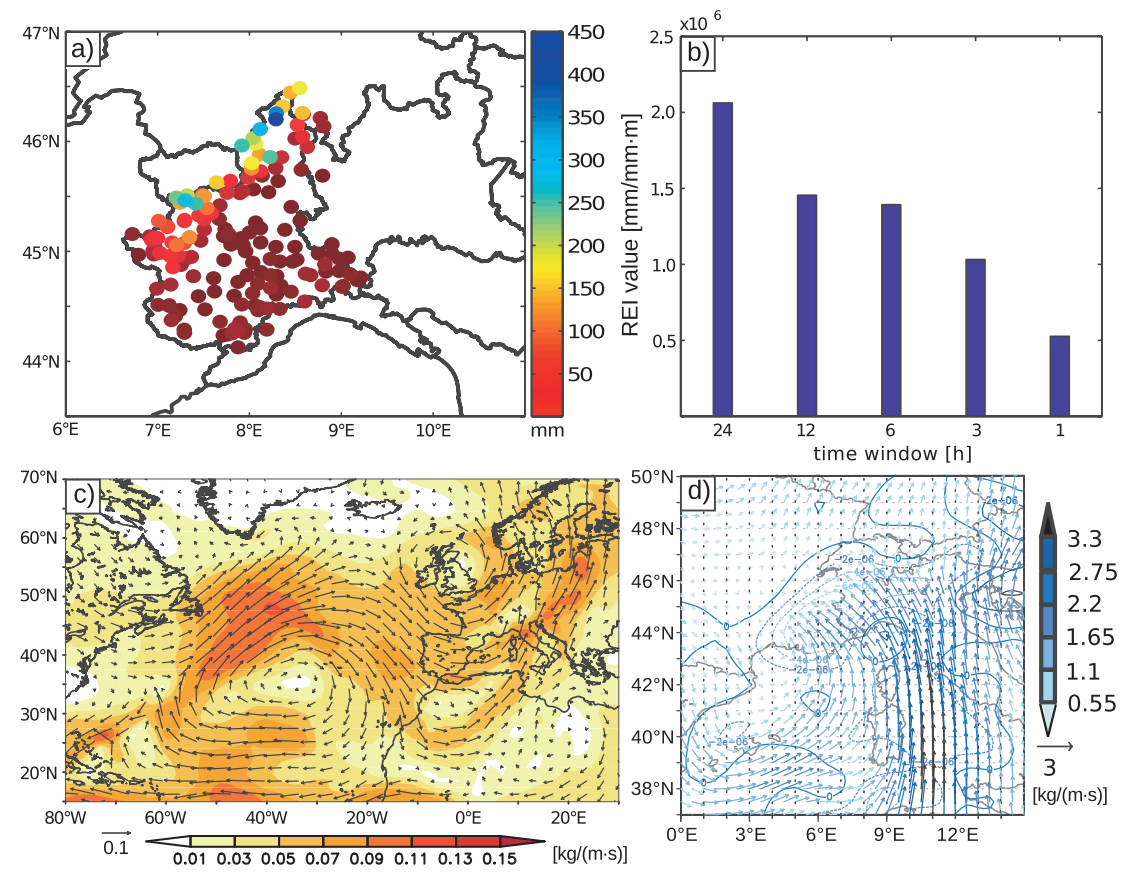

Figure 6. (a) stations marked as dots colored by (daily) rainfall amount measured on 14 October 2000; (b) intensity index of radius $K t[\mathrm{~mm} / \mathrm{mm} \mathrm{m}]$ for the available integration times between 13 October and 15 October 2000; (c) integrated humidity flux $[\mathrm{kg} /(\mathrm{m} \cdot \mathrm{s})]$ from $1000 \mathrm{hPa}$ to $700 \mathrm{hPa}$ shown as vectors on 13 October 2000 , the corresponding integrated humidity flux divergence $\left[\mathrm{kg} /\left(\mathrm{m}^{2} \cdot \mathrm{s}\right)\right]$ is contoured; (d) 3 day humidity advection $[\mathrm{m} / \mathrm{s} \cdot \mathrm{kg} / \mathrm{kg}$ ] from 10 October to 13 October, 1200 UTC shown as vectors. The magnitude is displayed as the shaded field.

"Imke"), and subsequent strong moisture advection into the study area. Over the Western MR, cyclone Josefine appears on 12 October ("1" in Figure 7a) on the cold front of the steering cyclone "Imke". As "Josefine" triggers the event, the moisture concentration over the Western MR reaches its peak (not shown). The continuous moisture advection towards the south side of the Alps remained until 15 October, associated with strong moisture convergence over Piemonte (cf. Figure 6d). These results document that part of the moisture originated from an airmass advected towards the MR and originally associated with tropical storm "Leslie", an assessment in accordance with, e.g., Turato et al. [2004]. The alpine orography plays a major role in focusing the event due to interactions with mesoscale atmospheric features [e.g., Nuissier et al., 2008; Ducrocq et al., 2008; Ricard et al., 2012].

[30] The second example corresponds to 21 September 1981, the element of cluster IV with the strongest values of $3 \mathrm{~h}$ REI. As expected, it was a more localized event, i.e., there is a smaller area covered by stations with $24 \mathrm{~h}$ and $12 \mathrm{~h}$ RAM (Figure 9a). A larger number of RAM are found for short durations ( 1 to $6 \mathrm{~h}$ ) than for longer durations (Figure 9b), unlike the majority of the events. The mean flow (cf. Figure 9c) bends close to Northwest Italy anticyclonically and is of southwestern direction over the target area. This event is also associated with a strong humidity advection over the
NA. The lower backward trajectories $(850 \mathrm{hPa})$ start over the Western MR and apparently pick up additional moisture over the MR (cf. Figure 8b). The upper trajectories (starting $700 \mathrm{hPa}$ ) trace back to the NA and bring additional moisture to this event (although by far not as much as in the previous example). The synoptic conditions exhibit a steering cyclone quasi-stationary over north England leading to strong northward flow towards the southern Alpine ranges. On 21 September, a cyclone developed over the Western MR, focusing the high humidity over the MR towards the Po Valley. The integrated humidity flux divergence (Figure 9d) shows a convergence in the northeast of the target area where also most of the RAM reporting stations are located. However, the anticyclonal flow over most part of the target area did not favor large-scale rainfall, which may explain the ratio between the intensity of the shorter time scales to the long ones.

[31] After analyzing the top 20 events, the typical local and synoptic conditions associated with the events can be summarized as follows:

[32] (a) Favorable large-scale conditions for the occurrence of deep convection (target area located in front of an upper air trough).

[33] (b) Enhanced humidity available over the eastern NA, which may be advected towards the MR in the following days under the influence of the steering low. 

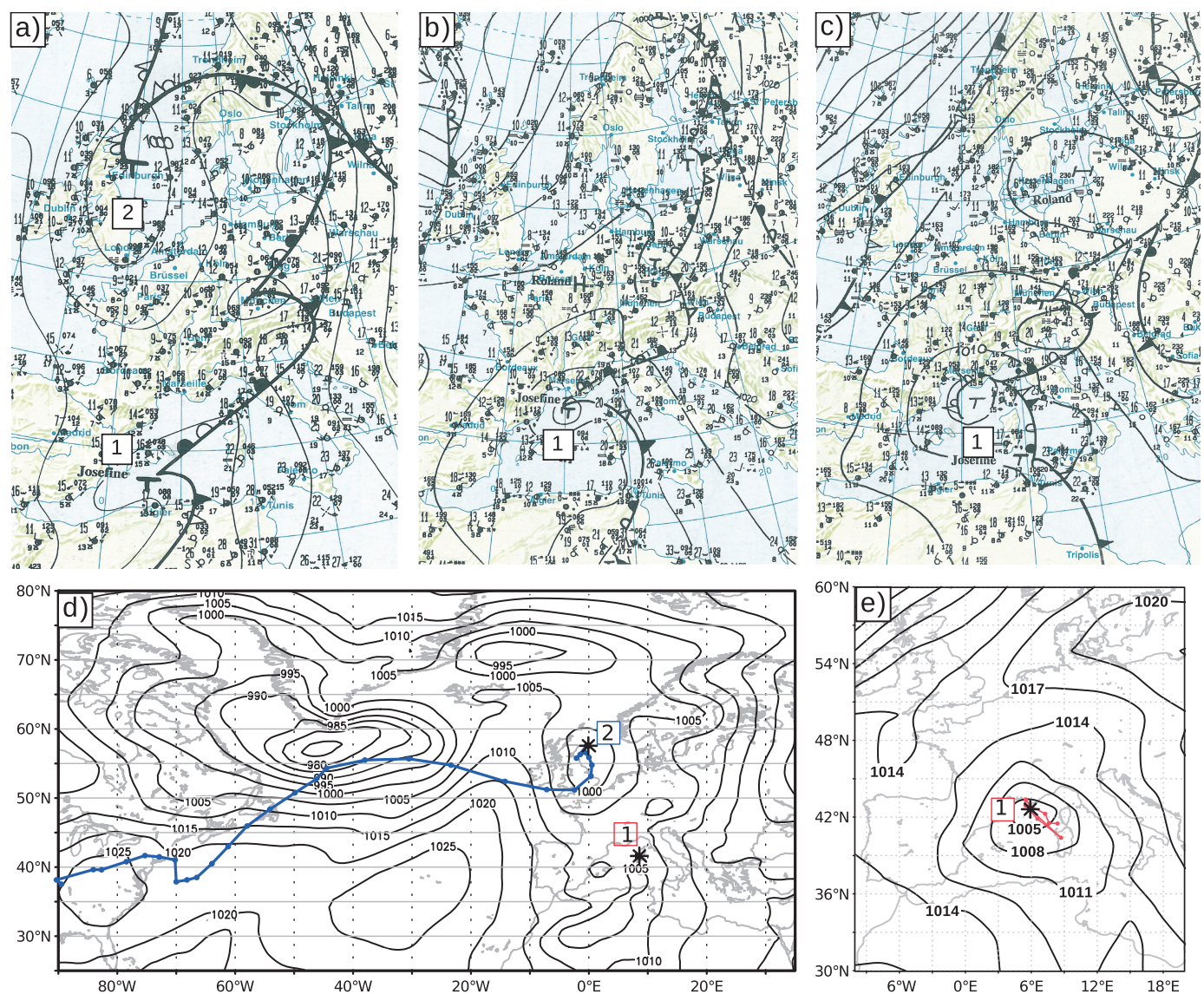

Figure 7. Surface pressure fields over Europe for (a) 13 October 2000, (b) 14 October 2000, and (c) 15 October 2000 [source: Berliner Wetterkarte]. (d) The ERA40 MSLP field of 13 October 2000, 0 UTC, the track of the cyclone (1) and (2) up to this time, the position of the cyclones at this time point is marked as a black star; (e) the MSLP field of 15 October 2000, 0 UTC and the track of cyclone (2) up to this time.
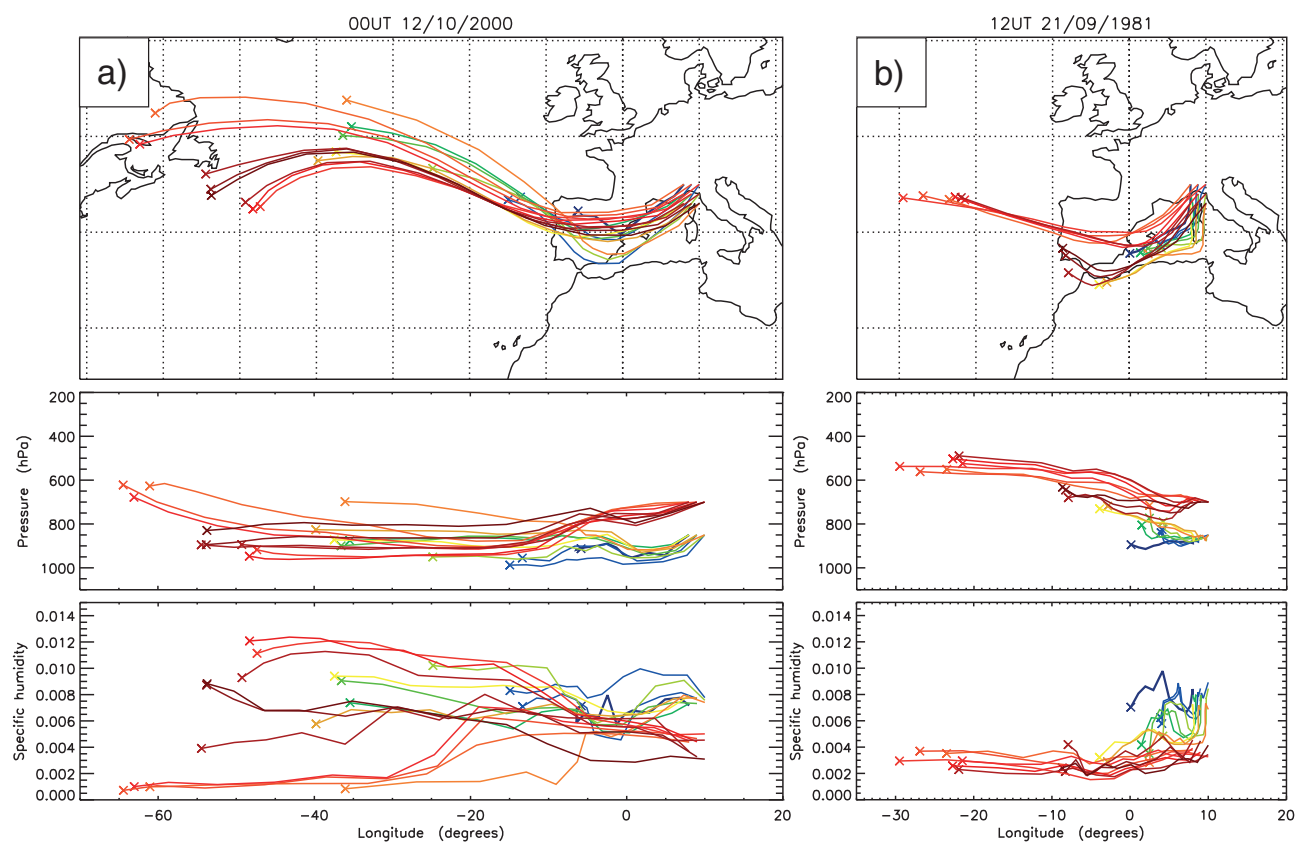

Figure 8. (a) horizontal path of 3 day backward trajectories started on 12 October 2000 at 1200 UTC, its vertical path (longitude versus pressure), and the contained humidity (longitude versus specific humidity); (b) as in Figure 8a but for 21 September 1981. Red colors indicate a starting level at $700 \mathrm{hPa}$, green/blue trajectories a starting level at $850 \mathrm{hPa}$. 

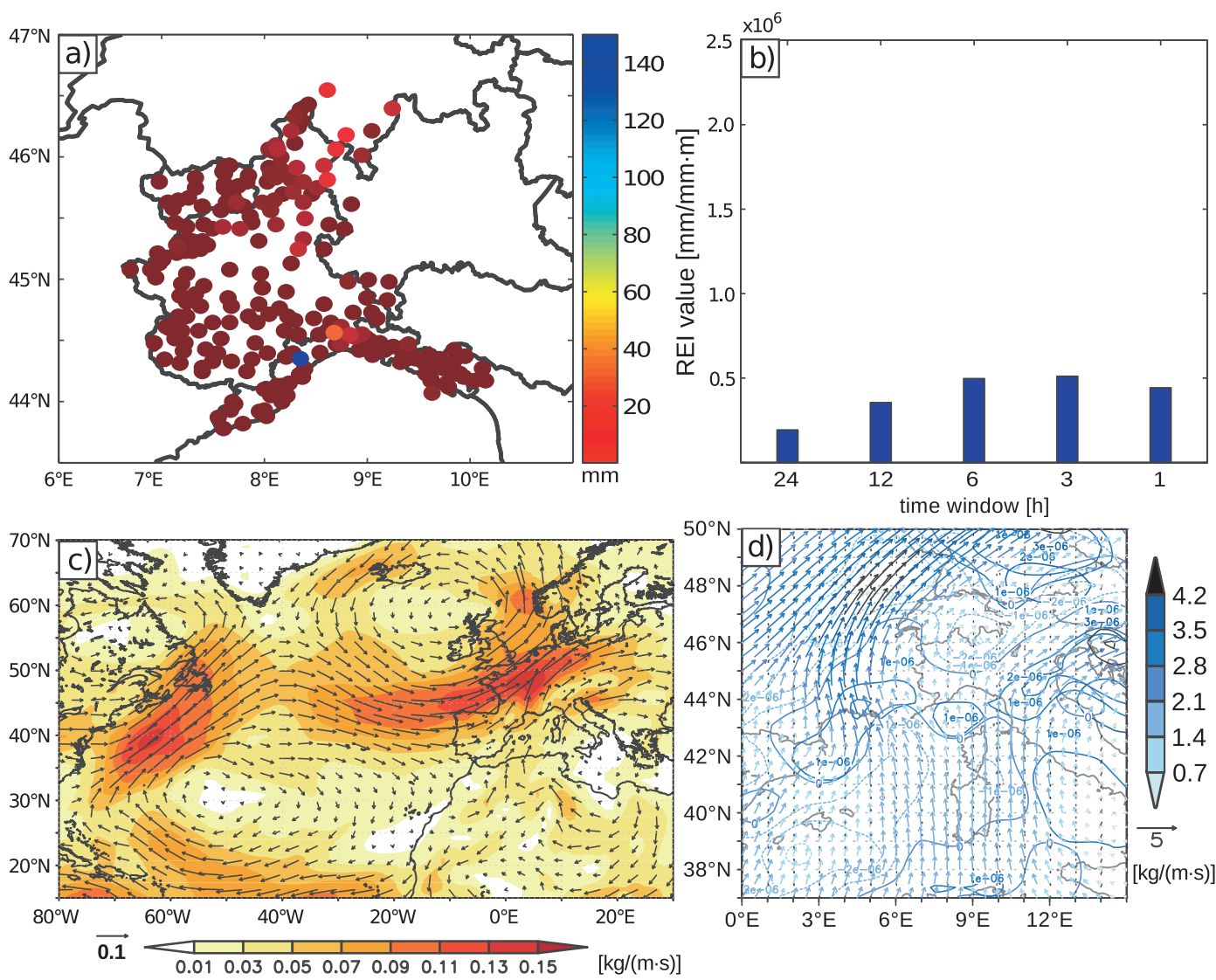

Figure 9. As in Figure 3 but for the 10th strongest event on 21 September 1981.

[34] (c) Enhanced humidity available over the Western MR shortly before the event.

[35] (d) Sustained moisture advection towards the southern Alpine ranges for days due to a quasi-stationary steering low located near the Bay of Biscay/British Isles.

[36] (e) Local cyclogenesis over the Western MR, which is responsible for triggering and focusing the event on a particular area.

[37] This characterization agrees with Rigo and Llasat [2007], who found a relationship of heavy rainfall and cyclones in Catalonia and with the results documented in, e.g., Jansá et al., 2001 and Martinez et al. [2008] for the Western MR.

\section{Conclusions}

[38] In this paper, the first two objectives were (i) to produce an objective classification based both on extreme rainfall amounts at different accumulation intervals and on spatial extension and (ii) to establish a ranking of extreme rainfall events based on the same hydrological motivated statistical methods. The method has been applied for Northwest Italy. A classification into ordinary and extraordinary events at the individual stations was performed following the statistical methodology developed in a hydrological context and applied to the RAM of $24 \mathrm{~h}$ duration [Boni et al., 2006]. This inherent use of normalized precipitation values allows the identification of strong precipitation events at stations, taking into account the station climatologies and thus their characteristic thresholds, which may differ for each station. Only events comprising at least one station with extraordinary rainfall were used for analysis. A clustering algorithm was applied, which separated the events into six clusters as a basis for further analysis. The ranking of events was performed combining intensity ranks at the individual stations and spatial extent. Verifications using the complete time series at individual stations for a subperiod suggested that the limitation of the main data set only comprising RAM was of minor importance. Results show that the top ranking events belonged to one cluster (cluster I). These events showed heavier-than-normal rainfall amounts on all considered durations and on extended spatial regions, particularly in terms of $24 \mathrm{~h}$ RAMs. The weaker events were assigned into clusters II to VI, with a decreasing intensity ranking. An exception is cluster IV, which contains events which were particularly strong on short durations. It must be assumed that the obtained statistics clearly owes to the fact that we used the $24 \mathrm{~h}$ duration as a basis for the selection of the events.

[39] Based on the identified six clusters, we demonstrated that events from the top clusters are strongly influenced by moisture advection from the NA Basin, while there is little influence for the weaker ones. Clusters I and II are characterized by strong and persistent upper air troughs reaching far south, located in a geographical position where they induce enhanced moisture advection from the NA into the Western MR. Further, they induce a strong northerly 
directed atmospheric flow towards the mountain ranges in the study area (Figure 4). The October 2000 event (Figure 6) is a prominent example. While similar characteristics can be found for the other clusters, flow intensities and moisture anomalies are progressively weaker with increasing cluster number. For clusters V and VI, there is little influence of moisture advection from outside of the MR. The clusters of moderate intensity (III and IV) show also interesting characteristics. Cluster III comprises typically large-scale forced rainfall events which typically feature long-ranging backward trajectories. In contrast, cluster IV events feature shorter but more humid trajectories, in line with the higher REI on the short durations.

[40] Based on the above described results, we conclude that moisture advection plays a relevant role in the magnitude of the extraordinary events considered in the present study. Thus, both the length and the humidity concentration along the backtrajectories are apparently factors contributing to high ranked events. We also checked these for the extreme events against trajectories and moisture advection for 50 nonextraordinary rainfall events. The latter typically show less influence from the NA Basin than the ones used as the main basis of our study. Still, it should be kept in mind that the NA is also a (secondary) climatological moisture source for the MR [Nieto et al., 2010; Drumond et al., 2011].

[41] In accordance with previous results from literature, autumn is the season observing most heavy rainfall events in the region considered [e.g., Rudari et al., 2005; Boni et al., 2006]. 54\% of the events labeled as extraordinary have occurred during this season, and the percentage reaches $80 \%$ when considering only the top 20 events. Only four top 20 events occur in spring (2), January (1), and late August (1). The accumulation of the most extreme extraordinary events in the autumn season may be explained by the conjugation of (remote) large-scale forcing and (local) regional forcing (see Table 1). While the large-scale conditions are more appropriate from autumn to spring, with the intrusion of large-scale troughs deep into the MR, the local conditions are actually better during summer and autumn, as the higher sea surface temperature and air temperatures strongly enhance the moisture availability and hence the potential for extreme events.

[42] The large-scale features associated with the events considered here are in a basic agreement to findings from other studies of extreme rainfall events in the Western MR. This result is expected, as it confirms similarities between the processes leading to the most intense events. The classification and the quantification of events according to spatial extension and local intensities performed in the present study and the combination with different aggregation times is, however, a novel approach. Another novel aspect is the demonstration that the role of moisture advection from the NA Basin increases progressively according to the events' magnitude. This is particularly true for $24 \mathrm{~h}$ RAM. For events characterized by RAMs predominantly on short time scales (cluster VI), evidence was provided that the relevance of moisture advection from the NA Basin is smaller.

[43] The classification of the events in terms of these impact-relevant characteristics can be used as a basis for more detailed studies, e.g., of the small-scale processes involved in the event genesis. The application of a mesoscale model on selected cluster members can help to identify common mesoscale features. Further studies could investigate effects of a modification of the initial selection of events, for example, selecting events under the condition that at least one station should see an extraordinary RAM on a short time scale.

[44] Acknowledgments. This work is partially supported by the European Union Programme Energy, Environment and Sustainable Development under the project CIRCE (contract 036961). CIMA acknowledges the Regional Environmental Protection Agencies of Liguria, Piemonte, and the Meteo-Hydrological Centre of Valle d'Aosta for providing the rainfall database. J.G.P. and S.U. thank CIMA research foundation for their hospitality during several visits to CIMA. J.G.P. acknowledges the support of the European Science Fundation (ESF) within the framework of the ESF activity on "Mediterranean Climate Variability and Predictability" MedCLIVAR. We also thank three anonymous reviewers for their constructive comments.

\section{References}

Beran, M. A., J. R. M. Hosking, and N. W. Arnell (1986), Comment on 'Two component extreme value distribution for flood frequency analysis' by Rossi et al.,1984, Water Resour. Res., 22, 263-266.

Boni, G., A. Parodi, and R. Rudari (2006), Extreme rainfall events: Learning from raingauge time series, J. Hydrol., 327, 304-314.

Boni, G., A. Parodi, and F. Siccardi (2008), A new parsimonious methodology of mapping the spatial variability of annual maximum rainfall in mountainous environments, J. Hydrometeor., 9, 492-506.

Buzzi, A., and S. Tibaldi (1978), Cyclogenesis in the lee of the Alps: A case study, Q. J. Roy. Meteorol. Soc., 104, 271-287.

Casas, M. C., B. Codina, A. Redano, and J. Lorente (2004), A methodology to classify extreme rainfall events in the western Mediterranean area, Theor. Appl. Climatol. 77, 139-150.

Cassardo, C., R. Cremonin, D. Gandini, G. Paesano, R. Pelosoni, and M. W. Qian (2001), Analysis of the severe flood of 13-16th October 2000 in Piedmont, Cuadernos de Investigacion Geografica, 27, 147-162.

Drumond, A., R. Nieto, E. Hernandez, and L. Gimeno (2011), A Lagrangian analysis of the variation in moisture sources related to drier and wetter conditions in regions around the Mediterranean Basin, Nat. Hazards Earth Syst. Sci., 11, 2307-2320.

Ducrocq, V., O. Nuissier, D. Ricard, C. Lebeaupin, and T. Thouvenin (2008), A numerical study of three catastrophic precipitating events over southern France. II: Mesoscale triggering and stationarity factors. $Q$. $J$. Roy. Meteorol. Soc., 134, 131-145.

Fragoso, M., R. M. Trigo, J. G. Pinto, S. Lopes, A. Lopes, S. Ulbrich, and C. Magro (2012), The 20 February 2010 Madeira flash-floods: Synoptic analysis and extreme rainfall assessment. Nat. Hazards Earth Syst. Sci., $12,715-730$.

Frei, C., and C. Schär (1998), A precipitation climatology of the Alps from high-resolution rain-gauge observations, Int. J. Climatol., 18, 873-900.

Gabella, M., and R. Mantonvani, (2001), The floods of 13-16 October 2000 in Piedmont (Italy): Quantitative precipitation estimates using radar and a network of gauges, Weather, 56: 337-343.

Gabriele, S., and N. Arnell (1991), A hierarchical approach to regional flood frequency analysis, Water Resour. Res., 27(6), 1281-1289.

Jansá, A., A. Genoves, M. A. Picornell, J. Campins, R. Riosalido, and O. Carretero (2001), Western Mediterranean cyclones and heavy rain. Part 2: Statistical approach, Meteorol. Appl., 8, 43-56, doi:10.1017/ S1350482701001049.

Krichak, S. O., P. Alpert, and M. Dayan (2004), Role of atmospheric processes associated with hurricane Olga in December 2001 flash floods in Israel, $J$ Hydrometeorol., 5, 1259-1270.

Llasat, M. C. (2001), An objective classification of rainfall events on the basis of their convective features. Application to rainfall intensity in the north-east of Spain, Int. J. Climatol., 21, 1385-1400.

Llasat, M. C., M. Barriendos, A. Barrera, and T. Rigo (2005), Floods in Catalonia (NE Spain) since the 14th century. Climatological and meteorological aspects from historical documentary sources and old instrumental records, J. Hydrol., 313, 32-47.

Martinez, C., J. Campins, A. Jansá, and A. Genoves (2008), Heavy rain events in the Western Mediterranean: An atmospheric pattern classification, Adv. Sci. Res., 2, 61-64.

Martius, O., E. Zenklusen, C. Schwierz, and H. C. Davies (2006), Episodes of Alpine heavy precipitation with an overlying elongated stratospheric intrusion: A climatology, Int. J. Climatol., 26, 1149-1164.

Massacand, A. C., H. Wernli, and H. C. Davies (1998), Heavy precipitation on the Alpine southside: An upper-level precursor, Geophys. Res. Lett., $25,1435-1438$

Methven, J. (1997), Offline trajectories: Calculation and accuracy, Tech. Report, 44, 18 pp., U.K. Univ. Global Atmos. Modelling Programme, Dept. of Meteorol., Univ. of Reading, Reading, U.K. 
Methven, J., M. Evans, P. Simmonds, and G. Spain (2001), Estimating relationships between air-mass origin and chemical composition, J. Geophys. Res., 106, 5005-5019.

Milelli, M., M. C. Llasat, and V. Ducrocq (2006), The cases of June 2000, November 2002 and September 2002 as examples of Mediterranean floods, Nat. Hazards Earth Syst. Sci., 6, 271-284.

Muller, M., M. Kaspar, and J. Matschullat (2009), Heavy rains and extreme rainfall-runoff events in Central Europe from 1951 to 2002, Nat. Hazards Earth Syst. Sci., 9, 441-450.

Murray, R. J., and I. Simmonds (1991), A numerical scheme for tracking cyclone centres from digital data. Part I: Development and operation of the scheme, Aust. Meteorol. Mag., 39, 155-166.

Nieto, R., L. Gimeno, A. Drumond, and E. Hernandez (2010), A Lagrangian identification of the main moisture sources and sinks affecting the Mediterranean area, WSEAS Trans. Environ. Develop., 5:6, 365-374.

Nuissier, O., V. Ducrocq, D. Ricard, C. Lebeaupin, and S. Anquetin (2008), A numerical study of three catastrophic precipitating events over southern France. I: Numerical framework and synoptic ingredients, Q. J. Roy. Meteorol. Soc., 134, 111-130.

Pinto, J. G., M. Klawa, U. Ulbrich, R. Rudari, and P. Speth (2001), Extreme precipitation events over southwestern Italy and their relationship with tropical-extratropical interactions over the Atlantic. In: Mediterranean storms (Deidda, R., A. Mugnai, and F. Siccardi, eds), pp 327-332, 3rd Plinius Conf., GNDCI Publication, Publ. No. 2560.

Pinto, J. G., T. Spangehl, U. Ulbrich, and P. Speth (2005), Sensitivities of a cyclone detection and tracking algorithm: Individual tracks and climatology, Meteorol. Z., 14, 823-838.

Ramos, M. C. (2001), Divisive and hierarchical clustering techniques to analyse variability of rainfall distribution patterns in a Mediterranean region, Atmos. Res., 57, 123-138.
Reale, O., L. Feudale, and B. Turato (2001), Evaporative moisture sources during a sequence of floods in the Mediterranean region, Geophys. Res. Lett., 28, 2085-2088.

Ricard, D., V. Ducrocq, and L. Auger (2012), A climatology of the mesoscale environment associated with heavily precipitating events over a northwestern Mediterranean area, J. Appl. Meteorol. Climatol., 51, 468-488.

Rigo, T., and M. C. Llasat (2007), Analysis of mesoscale convective systems in Catalonia using meteorological radar for the period 1996-2000, Atmos. Res., 83, 458-472, doi:10.1016/j.atmosres.2005.10.016.

Rossi, F., M. Fiorentino, and P. Versace (1984), Two component extreme value distribution for flood frequency analysis, Water Resour. Res., 20, 847-856.

Rudari, R., D. Entekhabi, and G. Roth (2005), Large-scale atmospheric patterns associated with mesoscale features leading to extreme precipitation events in Northwestern Italy, Adv. Water Res., 28, 601-614.

Siccardi, F. (1996), Rainstorm hazards and related disasters in the western Mediterranean region, Remote Sens. Rev., 14, 5-21.

Smith, R. B., and I. Barstad (2004), A linear theory of orographic precipitation, J. Atmos. Sci., 61, 1377-1391.

Svenisson, O. G. B., D. C. Boes, and J. D. Salas (2001), Population index flood method for regional frequency analysis, Water Resour. Res., 37(11), 2733-2748.

Uppala, S. M., and co-authors (2005), The ERA-40 re-analysis, Q. J. Roy. Meteorol. Soc., 131, 2961-3012.

Turato, B., O. Reale, and F. Siccardi (2004), Water vapor sources of the October 2000 Piedmont flood, J. Hydrometeorol., 5, 693-712.

Ward, J. H. (1963), Hierarchical grouping to optimize an objective function, J. Am. Stat. Assoc., 58, 236-244.

Winschall, A., S. Pfahl, H. Sodemann, and H. Wernli (2012), Impact of North Atlantic evaporation hot spots on southern Alpine heavy precipitation events, Q. J. Roy. Meteorol. Soc., 138, 1245-1258. 